\title{
Erratum
}

K. Iizuka and S. Yazawa 'The karyotype, C-bands and $\mathrm{AgNO}_{3}$-bands of a lungless salamander from Korea: Onychodactylus fischeri (Boulenger) (Amphibia, Urodela)': Experientia 50/2, (1994) 171-175.

We very much regret the omission of the caption of figure 3 on page 173. The caption should read as follows:

Figure 3. An $\mathrm{AgNO}_{3}$-banding karyotype of $O$. fischeri from Mt. Pukhan.

\section{EXPERIMENTAL WORLD}

News items and opinions from the sphere of the life sciences are reported in EXPERIMENTAL WORLD under the headings Science Policy, Research, Personalia/Prizes, Scene and Correspondence. All contributions are welcomed and should be sent directly to: Dr. M. J. Parnham, Von Guericke Allee 4, D-53125 Bonn, Germany. Tel. +49 (0)228 2591 29, Fax +49(0)228 256663 . 